University of Wollongong

Research Online

Illawarra Health and Medical Research Institute

Faculty of Science, Medicine and Health

2012

\title{
Application of the water needs index: Can Tho City, Mekong Delta, Vietnam
}

\author{
Magnus Moglia \\ CSIRO \\ Luis E. Neumann \\ CSIRO \\ Kim S. Alexander \\ Charles Sturt University, kim.alexander56@gmail.com \\ Mihn N. Nguyen \\ CSIRO \\ Ashok K. Sharma \\ CSIRO
}

See next page for additional authors

Follow this and additional works at: https://ro.uow.edu.au/ihmri

Part of the Medicine and Health Sciences Commons

\section{Recommended Citation}

Moglia, Magnus; Neumann, Luis E.; Alexander, Kim S.; Nguyen, Mihn N.; Sharma, Ashok K.; Cook, Stephen; Trung, Nguyen H.; and Tuan, Dinh D.A, "Application of the water needs index: Can Tho City, Mekong Delta, Vietnam" (2012). Illawarra Health and Medical Research Institute. 174.

https://ro.uow.edu.au/ihmri/174

Research Online is the open access institutional repository for the University of Wollongong. For further information contact the UOW Library: research-pubs@uow.edu.au 


\title{
Application of the water needs index: Can Tho City, Mekong Delta, Vietnam
}

\begin{abstract}
Provision of urban water supplies to rapidly growing cities of South East Asia is difficult because of increasing demand for limited water supplies, periodic droughts, and depletion and contamination of surface and groundwater. In such adverse environments, effective policy and planning processes are required to secure adequate water supplies. Developing a Water Needs Index reveals key elements of the complex urban water supply by means of a participatory approach for rapid and interdisciplinary assessment. The index uses deliberative interactions with stakeholders to create opportunities for mutual understanding, confirmation of constructs and capacity building of all involved. In Can Tho City, located at the heart of the Mekong delta in Vietnam, a Water Needs Index has been developed with local stakeholders. The functional attributes of the Water Needs Index at this urban scale have been critically appraised. Systemic water issues, supply problems, health issues and inadequate, poorly functioning infrastructure requiring attention from local authorities have been identified. Entrenched social and economic inequities in access to water and sanitation, as well as polluting environmental management practices has caused widespread problems for urban populations. The framework provides a common language based on systems thinking, increased cross-sectoral communication, as well as increased recognition of problem issues; this ought to lead to improved urban water management. Importantly, the case study shows that the approach can help to overcome biases of local planners based on their limited experience (information black spots), to allow them to address problems experienced in all areas of the city.
\end{abstract}

Keywords

index, city, needs, delta, water, can, vietnam, tho, application, mekong

Disciplines

Medicine and Health Sciences

Publication Details

Moglia, M., Neumann, L. E., Alexander, K., Nguyen, M. N., Sharma, A. K., Cook, S., Trung, N. H. \& Tuan, D. D.A. (2012). Application of the water needs index: Can Tho City, Mekong Delta, Vietnam. Journal of Hydrology, 468-469 (N/A), 203-212.

\section{Authors}

Magnus Moglia, Luis E. Neumann, Kim S. Alexander, Mihn N. Nguyen, Ashok K. Sharma, Stephen Cook, Nguyen H. Trung, and Dinh D.A Tuan 


\section{Application of the Water Needs Index: Can Tho City,}

\section{Mekong Delta, Vietnam}

Magnus Moglia ${ }^{\mathrm{a}}$ * (corresponding author), Luis E. Neumann ${ }^{\mathrm{a}}$, Kim S. Alexander ${ }^{\mathrm{b}}$, Minh N. Nguyen ${ }^{\mathrm{a}}$,

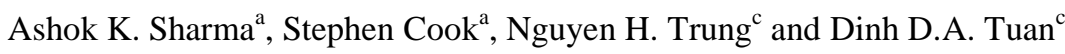

*Corresponding author: magnus.moglia@csiro.au, Phone: +61 39252 6025, Fax: +61 392526244

${ }^{a}$ CSIRO Land and Water, Graham Rd, Highett VIC 3190, Australia.

$7 \quad{ }^{\mathrm{b}}$ Institute of Land, Water and Society, Charles Sturt University, NSW. Australia.

$8{ }^{\mathrm{c}}$ College of Environment and Natural Resources, Can Tho University, 3/2 street, Campus 2, Can Tho, $9 \quad$ Vietnam.

10 Abstract

11 Provision of urban water supplies to rapidly growing cities of South East Asia is difficult 12 because of increasing demand for limited water supplies, periodic droughts, and depletion and 13 contamination of surface and groundwater. In such adverse environments, effective policy and planning processes are required to secure adequate water supplies. Developing a Water Needs Index reveals key elements of the complex urban water supply by means of a participatory approach for rapid and interdisciplinary assessment. The index uses deliberative interactions with stakeholders to create opportunities for mutual understanding, confirmation of constructs and capacity building of all involved. In Can Tho City, located at the heart of the Mekong delta in Vietnam, a Water Needs Index has been developed with local stakeholders. The functional attributes of the Water Needs Index at this urban scale have been critically appraised. Systemic water issues, supply problems, health issues and inadequate, poorly functioning infrastructure requiring attention from local authorities have been identified. Entrenched social and economic inequities in access to water and sanitation, as well as polluting environmental management practices has caused widespread problems for urban populations. The framework provides a common language based on systems thinking, increased cross-sectoral communication, as well 
as increased recognition of problem issues; this ought to lead to improved urban water management. Importantly, the case study shows that the approach can help to overcome biases of local planners based on their limited experience (information black spots), to allow them to address problems experienced in all areas of the city.

Key words: index; participatory assessment; urban water; water supply; Vietnam

\section{Introduction}

Many countries face challenges posed by increasing demand for limited water supplies, periodic droughts, and depletion and contamination of surface and groundwater (Moglia et al., 2008b; Timmer et al., 2007; UNDP, 2006; Vörösmarty et al., 2000; Wakidaa and Lerner, 2004). Many locations are experiencing severe water shortages and difficulties (Abu Zahra, 2001; Henriques, 2011) and urban areas are a critical component of the world's water crisis (Grohmann, 2009). This has implications for policy and planning processes required to secure adequate water supplies into the future (UNDP, 2006).

Concerted efforts to obtain accurate and comprehensive data on water resources are essential for planning purposes. Reliable and accurate information on the status and demand for water supply and sanitation services is typically unavailable, outdated or of questionable validity (Alexander et al., 2010; Molle and Mollinga, 2003). Difficulties arise in ascertaining the most important factors to consider in the management of water resources (Alexander et al., 2010; Barnett et al., 2008). Adopting a systems perspective can assist water planners responsible for infrastructure and supply management, yet analysis for the purposes of water planning can be an onerous and complex task (Moglia et al., 2012). Increasingly, participatory assessment is considered an approach that is useful in combining stakeholder engagement and knowledge elicitation (Barreteau, 2003; Daniell et al., 2010; Dray et al., 2006; Ribarova et al., 2011). Such modelling techniques can support collective decision-making in areas of natural resource management (Jones et al., 2009). A useful participatory assessment approach is the Water Needs Index (WNI), which minimises modelling activities while maximising integration of local knowledge 
(Alexander et al., 2011). The WNI has been based on the Climate Vulnerability Index developed by Sullivan and Meigh (2005) and extended by provision of involvement of local stakeholders in development and understanding of the index. The WNI is an interdisciplinary approach that can be used to identify systemic water issues and hotspots that require attention from local water authorities (Alexander et al., 2010; Alexander et al., 2011). The process involves a systems analysis using a weighted multi-criteria assessment within a hierarchy of dimensions and data sources. The key task is the definition of dimensions, and then the selection of data sources to be used to populate the dimensions. The selected data sources are either observations or proxies of the dimensions. While mathematical computations are straightforward, constructing the index and accessing suitable data is difficult and complex, with considerable subjective judgment required in the choice of dimensions. Reliability and accuracy of the data sources is also important to the process but the reliability and representativeness of chosen data sources may be often difficult to assess as data acquisition is often questionable. Alexander et al. (2010) discusses the inherent difficulties of inference that occur when using proxies. This can be in reference to problems of variable data quality, geographic scale, and differences in collection methods making the choice of indicators a matter of judgment.

There are often tendencies to overly simplify and provide deterministic explanations of the complex dynamics of the water cycle, and impacts on collection, use and storage. To alleviate as many concerns as possible and enhance legitimacy of assessments, the WNI methodology is embedded in a mixed methodological framework incorporating post-normal, adaptive methodologies that combine quantitative with qualitative methods of research, as per recommendations by Creswell (2009). The approach of developing an index based on a deliberative methodology had already been successfully tested in previous studies by the authors (Alexander et al., 2011; Moglia et al., 2009).

The WNI index typically incorporates a number of factors, using a deliberative process with 
al., 2009a; Alexander et al., 2009b; Alexander et al., 2010; Alexander et al., 2011; Moglia et al., 2008a; Moglia et al., 2010a). This process is a post-normal scientific approach that is useful when all factors are not necessarily knowable and where accessing all relevant information is too time consuming or unclear and affected by high levels of uncertainty (Funtowicz and Ravetz, 1993). The WNI methodology has been used to inform development of preliminary information embedded in Integrated Urban Water Management approaches which take a more holistic systems' perspective when planning for urban water management, as used in research by Maheepala et al. (2010). These approaches provide a means to manage water resources more sustainably by accounting for natural flows, water quality, water extraction, and balancing environmental and community needs.

This paper describes a study, Climate Adaptation though Sustainable Urban Development. The application of the WNI framework, described in this paper, has been a critical step in activity to understand the current situation of Can Tho City and to obtain data, aiming at setting up a good foundation for better urban water management in the study site. The WNI framework has helped provide a foundation for subsequent research by: 1) identifying the location specific urban water needs; 2) providing a frame of reference and a common language for the study; and 3) engaging stakeholders around a collective assessment of the problems which helps to legitimise study outcomes.

The paper is organised with descriptions of the: 1) case study context; 2) methodology including an initial workshop, a sector review and collation and analysis of selected data; 3) results and data; and finally 4) discussion and conclusions. The paper also describes some of the benefits of the WNI approach in terms of the study, as well as the benefits to local planners and decision makers.

Can Tho City is a fast growing city in the Mekong Delta of Vietnam. According to the local government urban planners the anticipated growth of residential, commercial, and industrial 
areas will be continuous, outstripping infrastructure that is already incapable of supplying the city needs (SIURP, 2010). In 2008, the city housed about 1.2 million inhabitants, and by 2020 the population is expected to increase to approximately 1.65 million (SIURP, 2010). In Can Tho City, there is an on-going migration of people from rural to urban areas , as is occurring all over the globe, and the percentage of urban population is expected to increase from $59 \%$ in 2008 to $70 \%$ in 2020 (SIURP, 2010). Rapid population growth and economic development has placed enormous pressure on the surrounding natural and built environments. In addition, investments in water-related infrastructure for supply and sanitation have not kept pace with urban growth, particularly in areas of rural-urban interface (Herbst et al., 2009). Likewise, there are growing concerns regarding a rapid degradation of river water quality, due primarily to the discharge of untreated wastewater from households, agriculture and industry (Herbst et al., 2009). The WNI describes the issues of infrastructure and access to services, groundwater systems, flooding concerns, and aquatic ecosystems, and these matters are described and discussed.

\subsection{Infrastructure and access to services}

119 Water and sanitation service in Can Tho City are provided by the Water Supply and Sanitation 120 Company (WSSC) in the main established urban settlements, with limited coverage in the periurban and rural areas (Neumann et al., 2011). The Centre of Clean Water and Environmental Sanitation (CCWES) of the Department of Agriculture and Rural Development (DARD) are responsible for servicing the peri-urban and rural areas, using community scale groundwater schemes. The largest pipe network services the Ninh Kieu district (see Figure 1), which is the most urbanised district of the city. The pipe network is also significant in urban areas along the Hau River from Binh Thuy to O Mon (see Figure 1). Smaller water supply networks service urban areas in the $\mathrm{O}$ Mon and Thot Not districts (see Figure 1), which are more distant to the main urban area. New urban development areas in South Can Tho (Cai Rang district, see Figure 1) are serviced by new water supply networks provided by developers. The water extracted from the rivers is treated at water treatment plants (WTPs) before distribution to households and businesses. There are currently eleven WTPs, seven of which are serving the five urban 
132 districts. The other four are serving the small towns of the rural districts. The total capacity of

133 the WTPs for the whole city is 129 ML/day.

\subsection{Groundwater systems}

135 Groundwater is a valuable resource for the community in Can Tho City and groundwater in the

136 Mekong Delta has been extracted for freshwater demand for over a century (Hung et al., 1998).

137 Household shallow tube-wells typically extract groundwater from a depth of 80-120 metres.

138 Groundwater wells for groundwater supply units and industrial uses access groundwater at a

139 depth of 100 to 250 metres (Thanh, 2008). A survey found that $60 \%$ of wells access the

140 Pleistocene aquifer (IUCN, 2011). Water quality analysis of monitored Can Tho wells

141 demonstrated elevated levels of total coliforms (Department of Natural Resources and

142 Environment, 2009). This could be indicative of pollution from inadequate sanitation systems

143 and infiltration of polluted urban runoff entering groundwater wells (Neumann et al., 2011). The

144 main trends threatening the sustainability of groundwater resources in Can Tho are declining

145 groundwater levels and declining groundwater quality. Over-exploitation of water sources,

146 saltwater intrusion and pollution are considered the reasons for the decline in groundwater

147 storage and quality by Neumann et al. (2011).

\subsection{Flooding issues}

149 The Mekong Delta has an annual water cycle impacted by upstream flows from the basin and

150 seasonal fluctuations in river flows from monsoonal precipitation events. Floods in the Mekong

151 are considered beneficial, with annual flooding relinquishing nutrients and sediment to the 152 floodplains. Large floods in the Mekong Delta, however, can typically lead to significant damage to houses, crops and infrastructure and may be hazardous to inhabitants (Tuan et al.,

154 2007). The monsoonal rainy season in Can Tho occurs between May to November, releasing 155 approximately $90 \%$ of the annual rainfall. During the rainy season, increased upstream flows, tidal surges and intense rainfall sometimes combine to cause widespread flooding across Can 
157 Tho City (Tuan et al., 2007). In addition, sea level rise and salt water intrusion is likely to be of

158 significant concern (current and/or future) for Can Tho City (Dragon Institute, 2009).

\subsection{Aquatic eco-systems}

The Mekong basin is one of the richest areas of biodiversity in the world (Gephart et al., 2010). The Mekong Delta ecosystem is critical for the region, providing sustenance through fisheries and the support of aqua-culture (Gephart et al., 2010). A number of aquatic species in the lower Mekong are listed as endangered or critically endangered (Dudgeon, 2000). Neumann et al (2011) has recognised that urban pollution, upstream development in the Mekong, overfishing, agriculture and aquaculture continue to place key pressures on ecosystems in the delta.

\section{Methodology and data}

The WNI methodology has been developed, justified and described in previous papers and reports (Moglia et al., 2008a; Alexander et al., 2009a; Alexander et al., 2009b; Alexander et al. 2010; Alexander et al. 2012). A workshop involving key stakeholders was held in October 2010 where the WNI framework (Alexander et al., 2010; Sullivan, 2002; Sullivan and Meigh, 2005), was adapted to the local context (Moglia et al., 2010a). In addition, an engagement process involving additional local stakeholders provided local knowledge to inform the development of the WNI. These processes informed a sector review, and identified available data sources (Neumann et al., 2011). A householder survey was undertaken to address information gaps in data (Neumann et al., 2012). The selection of indicators for the WNI occurred through a subjective process involving the national and international research teams and local stakeholders, in an iterative process over several months.

\subsection{Index methodology}

The WNI was developed within an index framework, drawing on the Climate Vulnerability Index (Sullivan and Meigh, 2005), which is an extension of the Water Poverty Index (Sullivan, 2002). The aim of the framework was to determine the water needs of a range of locations by incorporating the biophysical, economic and social drivers linking water, environment and 
poverty. The approach involved selection of indices used to identify systemic water issues and

184 identification of hotspots that require attention. The more constructive term 'Needs' was chosen

185 rather than the potentially pejorative term 'Poverty'. Initial applications of the WNI were at regional and national scales to inform funding priorities for investments in water aid (Moglia et al., 2008a). In response to case study learnings it was recognised that the WNI was useful when co-constructed with water managers at the catchment scale (Alexander et al., 2009a; Alexander et al., 2009b; Alexander et al., 2010). The first study application involving the WNI had six dimensions, i.e. Resources (R), Capacity Vulnerability (V) (Alexander et al., 2010). The generic calculation of the index is based on its dimensions using a weighted average:

$$
W N I=\left(R \cdot w_{R}\right)+\left(C \cdot w_{c}\right)+\left(U \cdot w_{U}\right)+\left(E \cdot w_{E}\right)+\left(A \cdot w_{A}\right)+\left(V \cdot w_{V}\right)
$$

Each of the dimension values are between 0 and 100, and the weights $\mathrm{w}_{\mathrm{k}}$ are all between 0 and 1 and add up to 1 as per Equation (2).

$$
w_{R}+w_{C}+w_{U}+w_{E}+w_{A}+w_{V}=1
$$

For the WNI, dimensions are changeable and are adjusted on the basis of the deliberation process outcomes.

\subsection{Workshop deliberation process}

200 The WNI workshop was designed to not only identify WNI dimensions and potential indicators,

201 but also to facilitate a broader discussion of the issues related to water within the region. 202 Specifically, the aims were to:

- Introduce the project and water risk concepts to stakeholders through interactive and practical activities.

- Confirm the geographical scope of the project, i.e. five urban districts of Can Tho City.

- Provide opportunity for local stakeholders to shape the project's focus. 
- Facilitate discussions on Can Tho City water and sanitation from a systems perspective.

- Generate a deeper understanding of the Can Tho City water and sanitation system and water needs, based on six dimensions of the WNI.

- Identify sources and acquisition of data relating to the six dimensions.

211 Key stakeholders were identified and invited to the workshop, on the basis of a stakeholder mapping exercise during previous scoping study trips, confirmed by Can Tho University ${ }^{1}$ and Institute of Sustainable Futures ${ }^{2}$ researchers involved in projects in the region. The stakeholder mapping exercise is described in the workshop report (Moglia et al., 2010a). Key participants included local staff from the WSSC, Department of Natural Resource and Environment (DONRE), Department of Planning \& Investment (DPI), Department of Labor, Invalids \&

217 Social Affairs (DoLISA), City Institute for Socio-Economic Development Studies (CIDS), 218 Department of Construction (DOC), and the Department of Agriculture and Rural Development 219 (DARD). This is a sub-set (8 out of 12) of the stakeholder organisations that were identified in 220 the stakeholder mapping exercise. Whilst all key stakeholders were invited, only some decided 221 to participate.

222 The workshop deliberation process occurred through the sequence of: 1) introduction of project, 223 2) description and discussion of the methodology, 3) definition of the six dimensions and their associated issues in the Can Tho City context, 4) exploration of the dimensions from a geographical perspective, and 5) discussion of the impacts of climate change and/or urban development on dimensions, and finally 6) discussion of and weighting (ranking) of the relative 227 importance of the dimensions. This process identified the important issues within the 228 dimensions, as well as available data sources. It was however found that many of the identified data sources were not in a spatial format, and hence unsuitable for the WNI, as used by 230 Alexander et al (2010). For the case study context (i.e. the more urbanised areas of Can Tho 231 City) it was perceived that the urban situation and the focus on climate change adaptation and

\footnotetext{
${ }^{1}$ For more details, see http://websrv.ctu.edu.vn/en/

${ }^{2}$ For more details, see http://www.isf.uts.edu.au/
} 
urban development warranted a different set of dimensions identified by the research team. The workshop assisted in determination of the dimensions and in discussions of the associated issues

234 Final dimensions are listed:

- Water and sanitation access (W): relating to households and other customers access

The workshop helped in identifying a range of data sources that could potentially be used to

249 quantify the WNI. Nine indicators were selected and used to quantify the six dimensions. The 250 indicators comprised social, economic, and biophysical measures as summarised in Table 1. 251 Data for each indicator was collected by the national research team based in Can Tho after identifying the data location and local departments and institutes responsible. The data was reviewed and synthesised into a coherent urban water sector review (Neumann et al., 2011). The

254 WNI dimensions were used to structure the review, and provided a qualitative analysis of the 255 situation in Can Tho. It was identified in the workshop and the subsequent review that there were gaps in the information available in terms of understanding the various aspects of the 
urban water systems. In order to explore some of the issues not covered by existing data, a survey of 1,200 households was undertaken (Neumann et al., 2012). This survey covered a number of wards (i.e. an administrative area in Can Tho, within a district), chosen to adequately represent the range of relevant situations in Can Tho City, and to cover a number of critical topics, such as; 1) impacts of flooding, 2) perceptions of water qualities, 3) quality and source of water that households use for different purposes, and 4) sanitation coverage, for which there existed only patchy or no information. The data from the household survey was extremely useful in quantification of the WNI and verification of key water supply issues.

In summary, the output of the WNI workshop, the data review, and the household survey (Moglia et al., 2010a; Neumann et al., 2012; Neumann et al., 2011) all informed the research team's understanding of the situation in Can Tho, and provided an information base to quantify the WNI. Table 1 shows the chosen indicators on the basis of this understanding and the workshop outcomes.

\section{SUGGESTED LOCATION FOR TABLE 1}

The dimensional weights (column 2 in Table 1) were applied as a weighted sum when aggregating dimensional values into the WNI value. The indicator weights (column 4 in Table 1) were applied in the weighted sum when aggregating indicator values into dimensional values. Water quality (Q) and Aquatic ecosystems (A) were assigned greater weight (0.3 as opposed to 0.1) because of their perceived relative importance by participants in the WNI workshop (Moglia et al., 2010a).

Weighting of importance of indicators was a subjective task undertaken by researchers reviewing workshop outcomes. As the sanitation situation in Can Tho City was more critical than the water supply, greater weight was given to the ability to access to sanitation $(0.9$ vs. 0.1). Furthermore, the number of connections per capita was seemingly inaccurate and a doubtful measure, more so than the reported percentage of the households that had access to "improved sanitation services". The dissolved oxygen in the dry season was critical and considered a more important indicator because values in the dry season were considerably lower 
than in the rainy season, indicating that eco-systems suffer particular hardship in the dry months. Dissolved oxygen was also considered a more pertinent indicator than the surface water quality measured in terms of coliforms and was allocated a greater weight ( 0.8 in total) in contrast to the weight for the measured coliforms (0.2).

The ranges (column 5 in Table 1) were used in the normalisation of data values, and calculated as indicator values ranging from 0 (indicating the lower end of the range) to 100 (indicating the upper end of the range). In the normalisation process, indicators were calculated such that 100 indicated a desirable situation, whilst 0 was particularly undesirable. In some instances, ranges were inverted, e.g. an indicator value of 0 indicated a top range value. For example, in the case of incidence of diarrhoeal disease, a higher rate of incidence indicated a worse outcome, translated into a lower dimensional value (worse outcome gives lower dimensional value). The WNI effectively normalised and standardised the information into a compatible format in which to comparatively assess the "water needs" of residents of Can Tho City.

\section{Calculation and results}

The WNI has been applied at the scale of wards. A ward in Can Tho is an administrative area, within a district. There are 44 wards within the 5 urban districts in Can Tho as shown in Figure 1, which also shows the estimated WNI scores in colours ranging from green (high score, i.e. good performance) to red (low score, i.e. bad performance). Each ward has a population of approximately 10,000-35,000 people. The current populations of the districts tends to vary from about 80,000 people in Cai Rang to about 215,000 people in Ninh Khieu.

\section{SUGGESTED LOCATION FOR FIGURE 1}

Collated data is presented in Table 1, and on this basis, dimensional values were calculated and presented in Table 2 . There were some limitations in the data sets in that they did not cover all of the wards, and in these cases an extrapolation process was used. This extrapolation used a weighted average of wards considered most similar in geographical location, land use and other pertinent factors depending on the particular ward. For example, for the purpose of the A 
310 dimension, a ward next to the main river (the Mekong) was considered similar to another nearby

311 ward upstream and downstream, but not be considered similar to a ward further inland without

312 direct river frontage.

Pearson product-moment correlation coefficients, varying between 1 and -1 , have also been calculated between the dimensions in the WNI, using values in Table 2 as inputs. A correlation coefficient near zero indicates very little co-variation between the two variables, whilst a higher correlation coefficient closer to 1 indicates that a high/low value in one variable tends to coincide with a high/low value in the other. A lower correlation coefficient perhaps closer to -1 indicates that a high value in one variable tends to coincide with a low value in the other (and vice versa). The dimensions that have a relatively strong correlation $(>0.4)$ with the WNI are $\mathrm{W}$, I and G. Perhaps not surprisingly, areas that were more urbanised had higher grade services (higher W), less (average) flooding risk (F) and superior infrastructure performance (I). On the other hand, these areas had higher indexes for polluted surface waters (A), likely due to the discharge of untreated wastewater, stormwater runoff and industrialization.

\section{Discussion}

The application of the WNI, as described in this paper provides a novel approach to the assessment of water needs across an urban area in a fast developing South East Asian regional centre. Assessing water needs in this context is important for the purposes of directing the attention of water planners and practitioners to more urgent and complex issues. As with any

330 approach, the reliability and accuracy of the assessment depends on the availability of data and the type of analysis conducted. We have shown that by using a household survey approach, in combination with surface water quality measurements, it was possible to undertake a relatively rapid assessment of water sector needs in Can Tho City. This approach can be used to assess water needs in any city in the world, although it can be argued that the selection of dimensions 
can be effectively achieved by means of a well established workshop process (Moglia et al., 2010a). The application of the WNI to the case study site of Can Tho City has enabled an exploration of a range of issues at both the district as well as at the ward scale, and it is clear that analysis at both levels provides useful insights into the complex water supply and sanitation needs within this city and surrounds.

In simplified terms, those areas that have poorer access to services, and infrastructure that is in poorer condition tend to have better environmental conditions (i.e. relating to surface water, risk of flooding and groundwater) and vice versa. This effect seems to even out the differences in the WNI score, and explains the impacts of a variety of factors implicated in water quality and supply issues for residents of Can Tho City.

\subsection{District WNI profiles}

The WNI of the districts in Can Tho City are shown in Table 3, on the basis of the average values in respective wards.

\section{SUGGESTED LOCATION FOR TABLE 3}

Based on the information in Table 2 and Table 3 the following conclusions have been postulated:

- In Ô Môn, the average district WNI value is approximately at the 5\%-percentile lowest WNI value for wards. Contributing to this, the W dimensional value in Ô Môn is close to the $10 \%$-percentile lowest value across all wards - indicating that a large proportion of the "poorest access" wards are in this area. Hence, this district would benefit considerably from better access to water supply and sanitation; especially as the Q dimensional value for the district is also very low, relating primarily to very poor health outcomes. It is premature to link the poor access as a causative factor for poor health outcomes, although this issue is explored by Neumann et al. (2012) who can clearly link health outcomes with type of water supply and type of sanitation. Detailed evaluation of the household survey data (Neumann et al., 2012) shows that utilisation of multiple 
water sources seems to be an indicator of a problematic water supply situation and poor health outcomes, and this is aligned with conclusions from a previous study in a different location (Moglia et al., 2008b, 2010b). It is suggested that a water safety assessment (AusAID, 2005) be undertaken for households in this ward to explore pathogen pathways, and how water safety may be improved. It is interesting to note that the initial workshop did identify concerns about the situation in Ô Môn but that such

- A very low dimensional value of 21 was recorded in Bình Thủy for the $\mathrm{G}$ dimension. This is consistent with the concerns raised in the workshop (Moglia et al., 2010a) about over-extraction and pollution of groundwater by industry in this area. Indeed, Bình Thủy is a district with significant industrial production, and it is largely recognised that whilst there exists regulation regarding groundwater extraction, there are currently only limited enforcement mechanisms in place. In summary, efforts should be made to help provide industry with cheap and readily accessible water in a way that does not limit economic development. Recycling of wastewater or basic treatment of surface water, in combination with the application of eco-industrial concepts appear good alternatives. 
390 Less severe, but also important, concerns identified were:

391

398

399

400

401

402

403

404

405

406

407

408

409

410

411

412

413

- Poor surface water quality and aquatic ecosystem condition in Ô Môn and in Cái Răng. These areas are also relatively urbanised.

- Poor water and sanitation access, as well as water quality (for human use) in Thốt Nốt is less than adequate. Thốt Nốt is an area that is similar in character to Ô Môn but where the location closer to the main river may alleviate some problems. Lack of access to adequate water and sanitation services in combination with poor environmental condition and poor surface water quality may be a particularly bad combination.

Table 3 also shows that the WNI captured a more holistic view of the urban water systems, and this can lead to unexpected results when compared to single measures such as access to water and sanitation. The Ninh Kieu district had the highest W (90) and I (78) indexes, and is second on Q and G. However, the district is third overall, as it has the lowest score in the A due to the poor state of its waterways, with high BOD and low dissolved oxygen, as well as elevated levels of other pollutants (Department of Natural Resources and Environment, 2009). This holistic assessment which provides an overall assessment (the WNI index), as well as scores for different indexes for each category, can then be used to identify and prioritise areas for investment and action. The results in Table 2 clearly show that the different wards require actions according to their outcome scores in the index, and a simple program targeting one of the index areas (such as access to water) is less effective than using the same funds to target different areas in different wards.

In terms of recommendations, the stand-out hotspot requiring the most urgent attention from local planners is the Ô Môn district where all but one ward has a WNI score below 50. However, the problems of Ô Môn are specific as the district appears to be relatively protected 
against flooding damage and the groundwater situation seems relatively better than in other districts.

\subsection{Ward WNI profiles}

417 Alexander et al. (2010) indicated that some indicators are more meaningful when applied at a 418 smaller geographical scale. In Can Tho, the relatively large size (scale) of the districts (which 419 contain a number of wards) sometimes obscured the water needs of specific areas within the 420 districts (hotspots) that significantly differ in comparison to those of the district as a whole. This is because the aggregation and subsequent average of spatially variable data from smaller units may smooth over extreme values, i.e., the modifiable area unit problem (Openshaw, 1984). Commonly, while a district may have a relatively high score in a dimension (for example groundwater condition) within the district there were wards that scored poorly against the dimension. For example, the older urban centre in Ninh Kiều had a ward that was highly vulnerable to flooding (Xuân Khánh). Other exceptions are depicted in Table 4.

\section{SUGGESTED LOCATION FOR TABLE 4}

The ward with the lowest WNI score (37) was in Thới Long in the Ô Môn district (see WNI profile in Figure 2). This was primarily caused by the combination of poor health outcomes, poor freshwater quality and lack of services, albeit having decent groundwater condition, reduced flood risk and reasonable infrastructure performance. The ward with the highest WNI score (63) was the An Cư ward in the Ninh Kiều district (see WNI profile in Figure 2), scoring highly in all dimensions except for the Aquatic ecosystems, where it scored very poorly. This clearly indicated the difference between two areas in the city: a highly urbanised and developed, versus a less urbanised, suffering from pollution, and performing poorly in terms of limited water and sanitation services. It is clear that the challenge that Can Tho City faces is to keep up with provision of services while ramping up efforts for environmental management and protection at a time of rapid population growth and economic development. 
440 The results from Figure 3 highlight once more the need for targeted action, with the Thoi Long

441 ward requiring improved water and sanitation access (W), while the $\mathrm{An} \mathrm{Cu}$ ward showed

442 satisfactory performance in most aspects but has concerns in terms of aquatic system with high

443 levels of BOD. This information is not only useful for administrators who must decide on

444 infrastructure prioritisation, but it is also useful for planners. The results from Figure 3 indicate

445 that any spending in water supply and sanitation in Thoi Long must include spending on

446 wastewater treatment and stormwater infrastructure; otherwise the improvement in one index

447 (W) will lead to a decline in another (A). Planners may consider that this is a priority area for

448 action, i.e., ensuring water services in areas where poor surface water quality is endemic. In this

449 sense, the geographic characteristics within an urban area is important. The community is likely

450 to be less vulnerable in areas of the city where pollution can be more easily washed out from

451 canals and rivers (better surface water quality) and with higher elevation (reduced flooding risk). Targeted management actions to alleviate the poorer water quality in these areas appear to 453 be worthwhile.

Based on our assessment, Can Tho City from a water needs perspective appears to be a "splintered" urban network, as described by Bakker (2010). There are islands of centralised public water supply (high in W), scoring high in most dimensions except for A due to more intense pollution in the highly urbanised areas. This is contrasted with the areas with Community Groundwater Schemes where drinking water quality is good, but where sanitation is 460 often inadequate. The surface water quality in the entire city is a cause for real concern, but the 461 quality is variable presumably due to local water flow patterns and local pollution loads. 462 Detailed exploration of water quality data reveals that this issue is particularly acute in the dry season.

464 The modern ideal of a large centralised system, which has been proposed in workshops, however seems inconceivable considering the large geographical size of the city and the apparent better performance of alternative water supplies in comparison to centralised piped 
supplies in Can Tho City (Neumann et al., 2012). The more promising water supply approach of using community groundwater schemes however seems limited by the apparent over-extraction and/or pollution of groundwater in some parts of the city, putting into question the need for more control and regulation.

\subsection{Observed benefits of the WNI process}

The WNI framework has been flexibly adapted to inform urban water resource management in three study sites, with varying success (Alexander et al., 2011). This paper describes its application in Can Tho City. The benefits from combining participatory procedures with modelling techniques has been the sharing of knowledge and information between local experts and with researchers through a simple, understandable and flexible approach to gathering data, opinions and providing a means to explore contentious topics. The idea is that elicited information can then be used to assist collective decision-making processes and in the establishment of a collective vision for the future management of resources. Specifically, the WNI workshop and related activities have helped in the following benefits, framed in the language of the framework used by Jones et al. (2009):

- Normative function: it is the distinct impression that the WNI application in Can Tho City has helped provide legitimacy of the assessments. This ought to increase the likelihood of finding coordinated solutions with wider buy-in from important stakeholders.

- Substantive function: the WNI application, and in particular the WNI workshop, helped initiate the sector review and to identify data sources related to pertinent topics (Neumann et al., 2011). Because of the increased buy-in into the process, it was also relatively easier to access data to support subsequent review and analysis.

- Instrumental function: perhaps the greatest benefit of the WNI application in Can Tho has been its function of creating a common language (i.e., dimensions, which have been clearly defined in terms of their scope). The process has also helped initiate ongoing 
collaboration in the project, and there is a strong sense that there is now a much greater acknowledgment of the need to collaborate and communicate between sectors, department and organisations.

In terms of outcomes of the activity from a participatory modelling perspective, there has been a clear sense of building collective knowledge and finding new ways of understanding the urban water system in Can Tho, for a variety of stakeholders. There is also a good likelihood of the activity evolving beyond the scope of this project.

\subsection{Dealing with geographical information bias}

501

This research has illustrated how the WNI process can be used at an urban scale to identify areas that require the most urgent attention in order to address local water needs. The evidence base is householder surveys and surface water quality measurements, and such data ought to be easy to collect and/or accessed by urban water practitioners and planners in most urban centres. It should be noted however that surface water quality monitoring data may be of variable reliability, in particular when there is significant temporal and/or spatial variability in measurement results. Hence caution in dependence on only one source of data is recommended. However, by using these sources of data, the WNI assessment process provides a transparent and more democratic way to highlight the water issues and supply concerns across an urban area.

Interestingly, it was noted by participants and observed by researchers in the WNI workshop (Moglia et al., 2010a) that most participants had limited knowledge of issues in more peripheral parts of the city, and consequently attention was often skewed toward areas about which details were better known. In fact, whilst Ô Môn (the district with lowest WNI score) was noted in the workshop as one area of concern, that judgment was also questioned strongly by other participants. Hence, uncertainty regarding the relative needs of different areas can be used to question the need for actions in these same areas. In fact when practical actions were discussed, the focus was mostly on parts of the cities that were well established and where the needs were more familiar. It can be hypothesised that, in particular in cultures with a low tolerance for 
ambiguity and uncertainty (Hofstede, 2001; Hofstede and Hofstede, 2004), such a bias in

521 information availability will have an impact on investment decisions. Vietnam has not been

522 assessed in terms of its cultural disposition towards uncertainty avoidance.

523 Such bias that is caused by limited information and experience may be one of the causal drivers for the well-known dilemma of provision of adequate services in the central areas of developing cities whilst services remain inadequate in the outer or peri-urban settlements (Bakker, 2010; Gerlach, 2008; Swyngedouw, 2004). At times, these areas of poor distribution can face water prices as much as 10, 20 or 400 times higher than those centrally supplied (Jouravlev, 2004). The authors believe that the WNI provides a way to address this bias if used to direct actions and attention at various scales and is applicable to most situations.

\subsection{Lessons for future applications of the WNI}

531 One may view the WNI as providing a common frame of reference, where each geographical location in the in the assessment is mapped against a six dimensional space. A couple of lessons regarding the use of WNI are as follows: both consideration of the temporal scale and the variability in aggregation practices are important; and creating a space for a systems perspective as part of day-to-day business is a worthwhile but challenging task.

536 A limitation of the WNI as it has been applied to date is that it is limited in the temporal scale.

537 A longitudinal study, tracking the WNI over time, would address this concern and is likely to provide some key insights into dynamics and drivers in the urban water system. It is

539 acknowledged that the ability to undertake such a study will be limited by the opportunity to

540 collect data of reasonable quality, such as by means of household surveys and water quality 541 measurements. Data from a longitudinal WNI study may furthermore provide a dataset that may 542 help in the parameterisation of an Agent-Based Model (Smajgl et al. 2011) representing the 543 dynamic nature of an urban system, as per Moglia et al. (2010b).

544 An important issue to consider in the application of the WNI is the variability within each 545 location. In this study, there is considerable variability within some of the wards and in such 
546 situations, the WNI dimensional values represent statistical means with higher variability. Other

547 wards are homogeneous, and in those situations WNI dimensional values represent a dominant

548 situation. This makes aggregation more difficult for some of the areas. For the areas with greater

549 variability, we have found it to be useful to collect complementary qualitative information such

550 as through interviews at a household scale. This allows for better understanding the underlying

551 factors and drivers that creates the situations.

552 Stakeholders tend to have a very sectoral focus, and it is a rare occurrence to find an

553 organisation, or even an individual that has adopted a systems perspective in their day to day

554 operations. In workshops however, individuals and organisations can clearly gain strong

555 insights by adopting a systems perspective. It will be important to support at least one local

556 institution to adopt a systems perspective in their day to day operations. This may perhaps be

557 achieved by means of knowledge brokers or boundary organisations

\section{Conclusions}

This paper describes the application of the WNI at an urban scale to the regional centre of Can

Tho City, Vietnam, located at the heart of the Mekong delta. The WNI provides an approach for rapid and interdisciplinary assessment of an urban water system that has an empirical foundation. The approach incorporates biophysical, economic and social drivers linking water, environment and poverty, which can be used to identify systemic water issues and identification of hotspots that require attention by local authorities. The data required for the application in Can Tho City, i.e., a household survey and water quality monitoring data, ought to be widely

566 available in most cities; although in many cases a household survey may need to be carried out

567 in situ by researchers. Several key functions of the WNI application process relates to stakeholder engagement outcomes, and in particular the emergent common language and integrated perspective amongst stakeholders. The WNI framework further provides a common frame of reference, i.e., a coordinated system with several dimensions that allows stakeholders to measure progress in urban water management performance and capacity into the future. In

572 the application in Can Tho City, it also emerged that the local stakeholders may be blinded to 
573 issues in certain areas, due to their limited knowledge about parts of the city with which they

574 were unfamiliar. Such blind spots are likely to exist because of the inherent social and economic

575 structures in the city, and may entrench existing inequities relating to water and sanitation

576 access as well as indicating different environmental management practices. The Water Needs

577 Index provides a framework for limiting the biases that water planners and stakeholders may

578 have, and the authors believe that its application can provide real value in future urban water

579 management and planning.

\section{Acknowledgements}

581 The study is part of a larger project, the Can Tho Case Study under the project 'Climate 582 Adaptation through Sustainable Urban Development' which has been jointly funded by AusAID 583 and CSIRO's Climate Adaptation Flagship through the AusAID / CSIRO Research For

584 Development Alliance. We would also like to acknowledge the support of the CSIRO Climate 585 Adaptation Flagship and our theme leader Dr Xiaoming Wang. The authors would like to thank 586 the Can Tho University team, led by Dr Nguyen Hieu Trung, Dr Nguyen Van Be and Mr Vu 587 Van Nam of Can Tho University, Vietnam for their great effort in collecting data. The authors would also like to thank Dr Mick Paddon, Ms Naomi Carrard, and Dr Juliet Willetts from the Institute for Sustainable Futures (ISF), for collaboration in the research project.

\section{References}

591 Abu Zahra, B.A.A., 2001. Water crisis in Palestine. Desalination 136(1-3) 93-99.

592 Alexander, K.S., Miller, C., Jovanovic, T., Moglia, M., 2009a. Tigum-Aganan Watershed Management Project, Part 2: Developing a Water Needs Index, Climate Adaptation National Research Flagship Report. CSIRO: Canberra, Australia.

Alexander, K.S., Moglia, M., Burn, S., 2009b. Informing future investment decisions for water and sanitation projects in the asia pacific by integrating statistical and qualitative information, 18th World IMACS Congress and International Congress on Modelling 
and Simulation: Interfacing Modelling and Simulation with Mathematical and Computational Sciences, MODSIM09: Cairns, QLD, pp. 2856-2862.

Alexander, K.S., Moglia, M., Miller, C., 2010. Water Needs Assessment: learning to deal with scale, subjectivity and high stakes. Journal of Hydrology 388(3-4) 251-257.

602

Alexander, K.S., Moglia, M., Tjandraatmadja, G.T., Nguyen, M., Larson, S., Trung, N.H., Barkey, R.A., 2011. Evaluation of Water Needs Index case studies, In: Chan, F.,

AusAID, 2005. Safe water guide for the Australian aid program 2005. AusAID: Canberra.

Bakker, K., 2010. Privatizing water: governance failure and the world's urban water crisis. Cornell University, New York, U.S.

Barreteau, O., 2003. Our Companion Modelling Approach. Journal of Artificial Societies and

Barnett, J., Lambert, S., Fry, I., 2008. The hazards of indicators: insights from the Social Simulation 6(2).

Creswell, J.W., 2009. Mapping the field of mixed methods research. Journal of Mixed Methods Research 3(2) 95-108.

Daniell, K.A., White, I., Ferrand, N., Ribarova, I.S., Coad, P., Rougier, J.E., Hare, M., Jones, N.A., Popova, A., Rollin, D., Perez, P., Burn, S., 2010. Co-engineering participatory water management processes: Theory and insights from Australian and Bulgarian interventions. Ecology and Society 15(4).

Department of Natural Resources and Environment, 2009. Report on Environment Quality Monitoring Can Tho City 10 Years (1999-2008) Center of Natural Resources and Environment Monitoring and Can Tho Department of Natural Resources and Environment: Can Tho City, Vietnam. 
Dragon Institute, 2009. Climate Change Impacts and Vulnerabilities Assessment for Can Tho City. Asian Cities Climate Change Resilience Network Program: Can Tho.

Dray, A., Perez, P., Jones, N., Le Page, C., D'Aquino, P., White, I., Auatabu, T., 2006. The AtollGame Experience: From Knowledge Engineering to a Computer-Assisted Role Playing Game. Journal of Artificial Societies and Social Simulation 9(1).

Dudgeon, D., 2000. Large scale hydrological changes in Tropical Asia: Prospects for riverince biodiversity. BioScience 50 (9) 793 -806.

Funtowicz, S.O., Ravetz, J.R., 1993. Science for the post-normal age. Futures 25 739-755.

Gephart, N., Blate, G., McQuistan, C., Thompson, C., 2010. New blood Greater Mekong new specieis discorives in 2009. WWF.

Gerlach, E., 2008. Regulating water services for Nairobi's informal settlements. Water Policy $10531-548$.

Grohmann, A., 2009. How urban areas can contribute towards easing the world-wide water crisis. Beitrag der urbanen räume zur linderung der weltweiten wasserkrise: notwendigkeiten und spielräume 150(7-8) 576-586.

Henriques, S., 2011. Too little, too hard to find: Addressing the global water crisis. IAEA Bulletin 53(1) 3-5.

Herbst, S., Benedikter, S., Koester, U., Phan, N., Berger, C., Rechenburg, A., Kistemann, T., 2009. Perceptions of water, sanitation and health: a case study from the Mekong Delta, Vietnam. Water Science \& Technology 60(3) 699-707.

Hofstede, G., 2001. Culture's Consequences, Comparing Values, Behaviors, Institutions, and Organizations Across Nations. Sage Publications, Thousand Oaks, CA.

Hofstede, G., Hofstede, G.-J., 2004. Cultures and Organizations: Software of the Mind. McGraw-Hill, New York, US.

Hung, D.T., Bang, N., Giang, P., 1998. Groundwater Resources of the Mekong Delta and Studying Areas. The Southern Geological Division of Hydrogeology and Engineering Geology. 
IUCN, 2011. Groundwater in the Mekong Delta - Discussion Paper, Mekong Water Dialogues. Ministry for Foreign Affairs of Finland.

Jones, N.A., Perez, P., Measham, T.G., Kelly, G.J., d’Aquino, P., Daniell, K.A., Dray, A., Ferrand, N., 2009. Evaluating Participatory Modeling: Developing a Framework for Cross-Case Analysis. Environmental Management 44(6) 1180-1195.

Jouravlev, A., 2004. Drinking water supply and sanitation services on the threshold of the XXI century: Santiago, Chile.

Maheepala, S., Blackmore, J., Diaper, C., Moglia, M., Sharma, A., Kenway, S., 2010. Integrated Urban Water Management Planning Manual. Water Research Foundation, Denver, CO.

Moglia, M., Alexander, K.S., Cook, S., Sullivan, C., Lane, B., Lipkin, F., 2008a. Regional and Country Scale Water Resource Assessment; Informing Investments in Future Water Supply in the Asia Pacific Region - a Decision Support Tool Water for a Healthy Country National Research Flagship Report Series. CSIRO: Melbourne, Australia.

Moglia, M., Burn, S., Tjandraatmadja, G., 2009. Vulnerability of water services in Pacific Island countries: combining methodologies and judgment. Water Science \& Technology 60(6) 1621-1631

Moglia, M., Cook, S., Nguyen, M., Trung, N., Paddon, M., Lipkin, F., Meharg, S., 2010a. Water risk index workshop in Can Tho, Vietnam.Case study on Urban Water Systems in Can Tho, Vietnam. CSIRO Climate Adaption Flagship,: Melbourne, Australia.

Moglia, M., Perez, P., Burn, S., 2010b. Modelling an urban water system on the edge of chaos. Environmental Modelling \& Software 25(12) 1528-1538. doi: 10.1016/j.envsoft.2010.05.002.

Moglia, M., Perez, P., Burn, S., 2008b. Water troubles in a Pacific atoll town. Water Policy 10(6) 613-637.

Moglia, M., Perez, P., Burn, S., 2012. Assessing the likelihood of realizing idealized goals: the case of urban water strategies. Environmental Modelling \& Software 35 50-60. 10.1016/j.envsoft.2012.02.005 
Molle, F., Mollinga, P., 2003. Water poverty indicators: conceptual problems and policy issues. Water Policy 5 529-544.

Neumann, L., Moglia, M., Cook, S., Nguyen, M., Sharma, A.K., Nguyen, T., 2012. Water use and sanitation in Can Tho City: challenges of urbanisation in the Mekong Delta. Urban Water Journal In Press.

Neumann, L., Nguyen, M., Moglia, M., Cook, S., Lipkin, F., 2011. Urban Water Systems in Can Tho, Vietnam: Understanding the current context for climate change adaption, Water for a Healthy Country National Research Flagship Report Series. CSIRO Land and Water: Melbourne, Australia.

Openshaw, S., 1984. The Modifiable Areal Unit Problem. Geo Books, Norwich, U.K.

Ribarova, I., Assimacopoulos, D., Jeffrey, P., Daniell, K.A., Inman, D., VamvakeridouLyroudia, L.S., Melin, T., Kalinkov, P., Ferrand, N., Tarnaki, K., 2011. Researchsupported participatory planning for water stress mitigation. Journal of Environmental Planning and Management 54(2) 283-300.

SIURP, 2010. Adjustment of Master Plan of Can Tho City to Year 2030, Synthesis Report. Southern Institute of Urban and Rural Planning, Ministry of Construction: Ho Chi Minh City, Vietnam.

Smajgl, A., Brown, D.G., Valbuena, D., Huigen, M.G.A., 2011. Empirical characterisation of agent behaviours in socio-ecological systems. Environmental Modelling \& Software $26(7) 837-844$.

Sullivan, C., 2002. Calculating a Water Poverty Index. World Development 30(7) 1195-1210.

Sullivan, C., Meigh, J., 2005. Targeting attention on local vulnerabilities using an integrated index approach: the example of the climate vulnerability index. Water Science and Technology 51(5) 69-78.

Swyngedouw, E., 2004. Social Power and the Urbanisation of Water: Flows of Power. Oxford University Press, New York, US.

Thanh, D.V., 2008. Household switching behaviour in the use of groundwater in the Mekong Delta, Vietnam. Economy and Environment Program for Southeast Asia. 
Timmer, D.K., de Loë, R.C., Kreutzwiser, R.D., 2007. Source water protection in the Annapolis Valley, Nova Scotia: Lessons for building local capacity. Land Use Policy 24(1) 187198.

Tuan, L.A., Hoanh, C.T., Miller, F., Sinh, B.T., 2007. Floods and Salinity Management in the Mekong Delta, Vietnam, In: Be, T.T., Sinh, B.T., Miller, F. (Eds.), Challenges to Sustainable Development in the Mekong Delta: Regional and National Policy Issues and Research Needs.

UNDP, 2006. Human Development Report. Beyond scarcity: Power, poverty and the global water crisis. United Nations: New York.

Vörösmarty, C.J., Green, P., Salisbury, J., Lammers, R.B., 2000. Global Water Resources: Vulnerability from Climate Change and Population Growth. Science 289(5477) 284-288 DOI: $10.1126 /$ science.289.5477.284

Wakidaa, F.T., Lerner, D.N., 2004. Non-agricultural sources of groundwater nitrate: a review and case study. Water Research 39 3-16.

\section{Figure captions}

Figure 1. Location of surveyed wards in Can Tho City.

Figure 2: WNI profiles of the highest and lowest scoring wards in Can Tho City

\section{Table captions}

Table 1: Chosen indicators (input) for the WNI application in Can Tho City

Table 2: WNI calculated for the wards of Can Tho

Table 3: WNI values for the districts of Can Tho City

Table 4: Exceptions to district scale recommendations 
Table 1: Chosen indicators (input) for the WNI application in Can Tho City

\begin{tabular}{|c|c|c|c|c|}
\hline $\begin{array}{l}\text { WNI } \\
\text { dimension }\end{array}$ & $\begin{array}{l}\text { Dimensional } \\
\text { Weight }\end{array}$ & Chosen indicators & $\begin{array}{l}\text { Indicator } \\
\text { weight }\end{array}$ & Range \\
\hline \multirow{2}{*}{$\begin{array}{l}\text { Water \& } \\
\text { sanitation } \\
\text { Access }(\mathbf{W})\end{array}$} & \multirow[b]{2}{*}{0.1} & $\begin{array}{l}\text { Connections per capita to piped water supply or } \\
\text { community based groundwater schemes }{ }^{d}\end{array}$ & & \\
\hline & & $\begin{array}{l}\text { Percentages of householders with lack of access } \\
\text { to improved sanitary services, i.e. this means } \\
\text { survey responses Other and Hanging Toilet }\end{array}$ & 0.9 & $\begin{array}{c}0- \\
52 \%\end{array}$ \\
\hline $\begin{array}{l}\text { Quality of } \\
\text { Accessed } \\
\text { Water }(\mathbf{Q})\end{array}$ & 0.3 & $\begin{array}{l}\text { Incidence of water related illness, i.e. percentage } \\
\text { of households reporting to have been sick with } \\
\text { diarrhoeal disease }^{e}\end{array}$ & 1.0 & $\begin{array}{c}0- \\
19 \%\end{array}$ \\
\hline \multirow[t]{2}{*}{$\begin{array}{l}\text { Aquatic } \\
\text { ecosystems } \\
\text { (A) }\end{array}$} & \multirow[t]{2}{*}{0.3} & $\begin{array}{l}\text { Dissolved Oxygen measured in } \mathrm{mg} / \mathrm{l} \text { - measured } \\
\text { in January to July } 2011 \text { (dry season) }^{\mathrm{f}} \\
\text { Dissolved Oxygen measured in } \mathrm{mg} / \mathrm{l} \text { - measured } \\
\text { in July to December } 2011 \text { (rainy season) }^{f}\end{array}$ & 0.7 & $3-8^{c}$ \\
\hline & & $\begin{array}{l}\text { Surface water quality measured in terms of Total } \\
\text { Coliform }(\mathrm{MPN} / 100 \mathrm{ml})^{f}\end{array}$ & 0.2 & $\begin{array}{c}930- \\
51,150\end{array}$ \\
\hline Flooding (F) & 0.1 & $\begin{array}{l}\text { Percentage of households who have had their } \\
\text { houses flooded }{ }^{e}\end{array}$ & 1.0 & $6-49 \%$ \\
\hline $\begin{array}{l}\text { Infrastructure } \\
\text { performance } \\
\text { (I) }\end{array}$ & 0.1 & $\begin{array}{l}\text { Percentage of the households reporting that the } \\
\text { pressure is inadequate, and or have supply for } \\
\text { less than } 18 \text { hours of the day e }\end{array}$ & 1.0 & $0-64 \%$ \\
\hline $\begin{array}{l}\text { Groundwater } \\
\text { issues }(\mathbf{G})\end{array}$ & 0.1 & $\begin{array}{l}\text { Percentage of households reporting depletion } \\
\text { and/or pollution of groundwater resources }{ }^{\mathrm{e}}\end{array}$ & 1.0 & $0-90 \%$ \\
\hline
\end{tabular}

a Note: The range for the lack of sanitation access has been defined on the based on the range of values, but excluding two outliers. Taking into account these two outliers, the observed range is $0-67 \%$. 
${ }^{b}$ Note: The range for the incidence of water related disease has been calculated after removing two outliers. Taking into account these two outliers, the observed range is $0-37.5 \%$.

c Note: The range for the Dissolved Oxygen has been defined on the basis of what is the expected impact on ecosystems rather than what is observed in the range of values. The true range of values is $2.12-5.78$. Higher values indicate a healthier water environment.

${ }^{d}$ Note: Data collected from the WSSC and the CCWS in 2011, by the Can Tho University.

e Note: Data collected by means of household survey in Can Tho of 1200 households.

fNote: Data collected from DONRE in 2011 by the Can Tho University 
Table 2: WNI calculated for the wards of Can Tho

\begin{tabular}{|c|c|c|c|c|c|c|c|c|}
\hline Ward & District & $\mathbf{W}^{*}$ & $\mathbf{Q}^{*}$ & $A^{*}$ & $F^{*}$ & $I^{*}$ & $\mathbf{G}^{*}$ & WNI \\
\hline Cái Khế & & 92 & 69 & 26 & 73 & 77 & 73 & 53 \\
\hline An Hòa** & & 90 & 63 & 11 & 58 & 78 & 95 & 60 \\
\hline Thới Bình & & 91 & 60 & 11 & 70 & 87 & 97 & 54 \\
\hline An Nghiệp & & 92 & 69 & 11 & 67 & 81 & 84 & 56 \\
\hline $\mathrm{AnC} \boldsymbol{u}^{* *}$ & & 93 & 86 & 3 & 94 & 78 & 100 & 56 \\
\hline An Hội** & & 93 & 57 & 6 & 81 & 96 & 100 & 63 \\
\hline Tân $\mathrm{An}^{* *}$ & Ninh Kiều & 78 & 42 & 20 & 81 & 100 & 20 & 56 \\
\hline An Lạc & & 85 & 60 & 5 & 85 & 88 & 59 & 47 \\
\hline An Phú ${ }^{* *}$ & & 93 & 77 & 3 & 88 & 76 & 98 & 51 \\
\hline Xuân Khánh"* & & 90 & 66 & 2 & 0 & 67 & 26 & 60 \\
\hline Hưng Lợił* & & 92 & 78 & 12 & 42 & 57 & 24 & 39 \\
\hline An Khánh & & 94 & 70 & 6 & 50 & 67 & 59 & 49 \\
\hline An Bình & & 80 & 78 & 36 & 35 & 62 & 19 & 50 \\
\hline An Thó'i** & & 94 & 90 & 41 & 66 & 50 & 20 & 60 \\
\hline Bình Thủy & & 88 & 78 & 41 & 46 & 67 & 33 & 62 \\
\hline Trà Nóc & & 52 & 85 & 42 & 69 & 64 & 15 & 59 \\
\hline Long Hòa & & 65 & 89 & 41 & 60 & 62 & 22 & 58 \\
\hline Long Tuyền** & & 37 & 100 & 38 & 65 & 55 & 26 & 60 \\
\hline Thới An Đông** & & 40 & 100 & 40 & 75 & 57 & 12 & 60 \\
\hline
\end{tabular}




\begin{tabular}{|c|c|c|c|c|c|c|c|c|}
\hline Trà An & & 55 & 95 & 41 & 68 & 60 & 17 & 60 \\
\hline Bùi Hữu Nghĩa & & 65 & 89 & 41 & 60 & 62 & 22 & 60 \\
\hline Châu Văn Liêm** & & 45 & 0 & 40 & 84 & 69 & 77 & 41 \\
\hline Thới Hòa & & 21 & 0 & 39 & 81 & 71 & 84 & 39 \\
\hline Thới Long & & 1 & 38 & 30 & 97 & 69 & 87 & 37 \\
\hline Long Hưng & Ô Môn & 53 & 0 & 43 & 59 & 76 & 86 & 46 \\
\hline Thới An & & 21 & 6 & 43 & 89 & 69 & 84 & 40 \\
\hline Phước Thới** & & 28 & 75 & 37 & 86 & 69 & 0 & 41 \\
\hline Trường Lạc & & 35 & 0 & 38 & 85 & 69 & 38 & 52 \\
\hline Lê Bình & & 69 & 59 & 36 & 64 & 67 & 38 & 56 \\
\hline Hưng Phú** & & 75 & 84 & 24 & 56 & 70 & 93 & 52 \\
\hline Hưng Thạnh & & 53 & 77 & 40 & 29 & 67 & 14 & 62 \\
\hline Ba Láng & i Răng & 57 & 70 & 40 & 83 & 61 & 44 & 51 \\
\hline Trường Thạnh & & 64 & 80 & 40 & 42 & 68 & 54 & 57 \\
\hline Phú Thứ** & & 80 & 40 & 44 & 100 & 67 & 62 & 59 \\
\hline Tân Phú & & 66 & 59 & 44 & 64 & 67 & 38 & 56 \\
\hline Thốt Nốt** & \multirow{4}{*}{ Thốt Nốt } & 63 & 6 & 46 & 33 & 83 & 96 & 46 \\
\hline Thới Thuận & & 50 & 48 & 43 & 71 & 42 & 12 & 43 \\
\hline Trung Nhứt ${ }^{* *}$ & & 22 & 53 & 40 & 92 & 0 & 92 & 45 \\
\hline Thuân An & & 2 & 52 & 40 & 83 & 42 & 92 & 48 \\
\hline
\end{tabular}




\begin{tabular}{|c|c|c|c|c|c|c|c|}
\hline Thanh Hoa & 1 & 26 & 42 & 80 & 42 & 100 & 49 \\
\hline Thuận Hưng & 59 & 57 & 36 & 68 & 42 & 51 & 43 \\
\hline Tân Lộc & 44 & 29 & 46 & 63 & 42 & 72 & 50 \\
\hline Trung Kiên & 47 & 29 & 46 & 64 & 42 & 30 & 45 \\
\hline Tân Hưng & 26 & 47 & 40 & 83 & 55 & 69 & 41 \\
\hline
\end{tabular}

${ }^{*}$ Note: some of these numbers have been estimated based on extrapolation. The extrapolation has been based on averaging values based on surrounding areas.

${ }^{* *}$ Note: rows in dark grey signify wards where the WNI dimensions have been established without extrapolation, and rows in lighter grey signify wards where the WNI dimensions have been established with extrapolation in only one of the underlying dimensions. 
Table 3: WNI values for the districts of Can Tho City

\begin{tabular}{|l|c|c|c|c|c|c|c|}
\hline & W & Q & A & F & I & G & WNI \\
\hline Ô Môn & 29 & 17 & 39 & 83 & 70 & 65 & 41 \\
\hline Thốt Nốt & 35 & 38 & 42 & 71 & 43 & 68 & 46 \\
\hline Ninh Kiều & 90 & 67 & 12 & 63 & 78 & 66 & 53 \\
\hline Cái Răng & 66 & 67 & 38 & 63 & 67 & 49 & 56 \\
\hline Bình Thủy & 62 & 91 & 41 & 64 & 60 & 21 & 60 \\
\hline
\end{tabular}


Table 4: Exceptions to district scale recommendations

\begin{tabular}{|l|l|l|}
\hline District & Ward & Significant exception \\
\hline Ô Môn & Phước Thới & Poor groundwater condition (I) \\
\hline Cái Răng & Phú Thứ & Poor water quality (Q) \\
\hline Cái Răng & Hưng Phú & Poor surface water quality (A) \\
\hline Cái Răng & Hưng Thạnh & High flood risk (F) \\
\hline Bình Thủy & Long Tuyền and Thới An Đông & Poor water and/or sanitation access (W) \\
\hline Thốt Nốt & Trung Nhứt & Poor infrastructure performance (I) \\
\hline Thốt Nốt & Thới Thuận & Poor groundwater condition (G) \\
\hline Thốt Nốt & Thốt Nốt & Poor water quality (Q) \\
\hline Ninh Kiều & Xuân Khánh & High flood risk (F) \\
\hline Ninh Kiều & Tân An & Poor water quality (Q) \\
\hline Ninh Kiều & Tân An, Xuân Khánh, Hưng Lợi and & Poor groundwater condition (I) \\
\hline & An Bình & \\
\hline
\end{tabular}


We have undertaken a case study of the Water Needs Index.

The case study site is in Can Tho City, in the Mekong Delta of Vietnam.

The Water Needs Index maps six dimensions, relating to a socio-technical and biophysical aspects.

The method has been shown to support Integrated Urban Water Management.

The Water Needs Index can help planners to tackle information black spots. 